\title{
In the Land of Black and White, Microbial Deposition of Ferromanganese on the Walls of Snowy River, Ft Stanton Cave, NM
}

Michael Spilde, Jason Kimble, Diana Northup

University of New Mexico

Penelope Bostion

New Mexico Institute of Mlining \& Techinology and NASAAnnes Research Ceniter 
The Snowy River Passsage

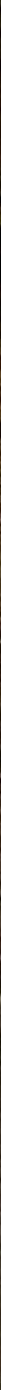

Ft Stanton Cave: $50+\mathrm{km}$ of surveyed passage (14 $4^{\text {th }}$ longest in US) Snowy River: $19.1 \mathrm{~km}$ long and still going! 


\section{Geology of Ft Stanton Cave}

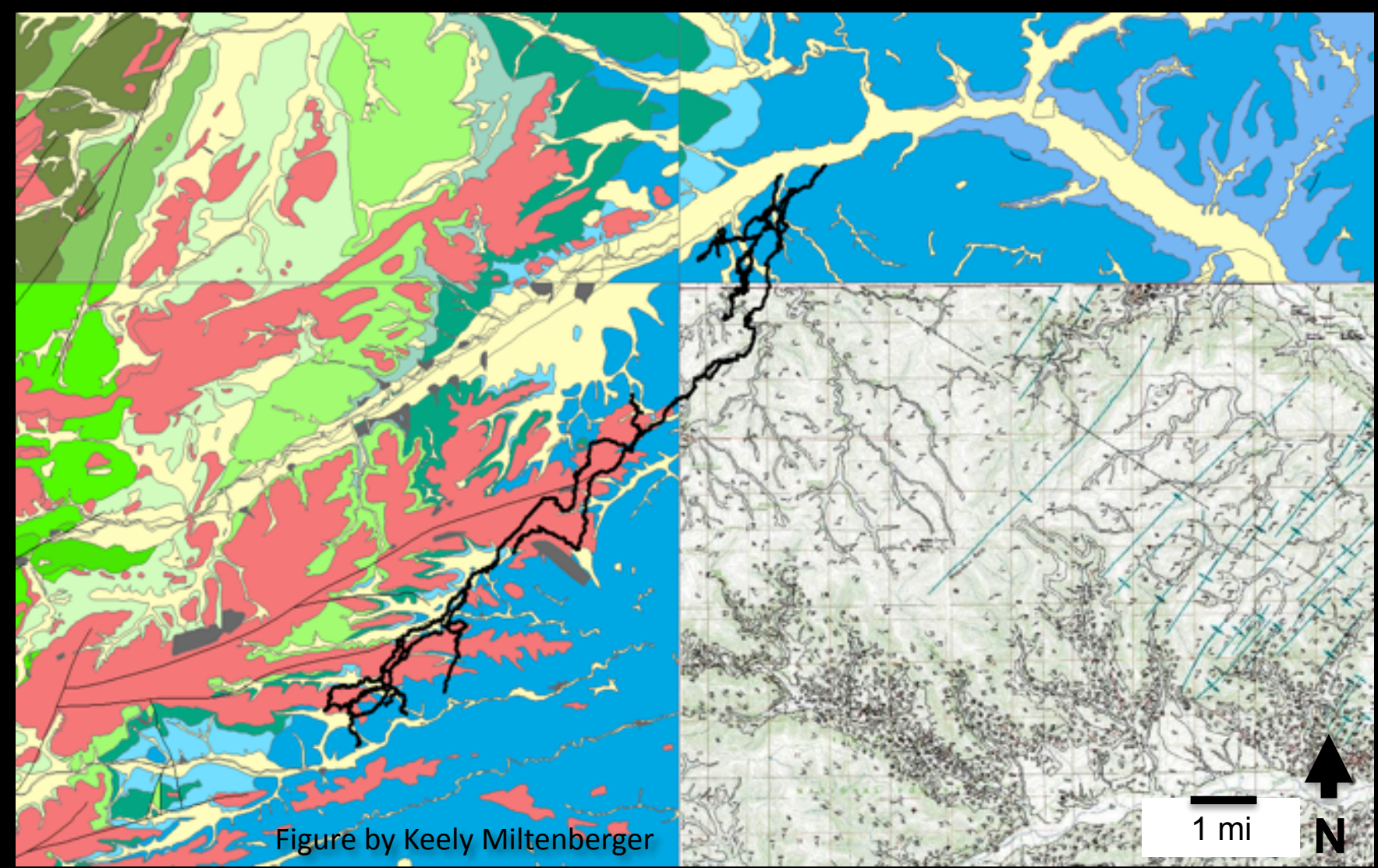

- Cave is hosted in Permian San Andres Limestone

- Soils above the cave developed in mainly limestone and Tertiary gravels (stay tuned for the next talk!)

- Likely source of water in Snowy River is $6 \mathrm{~km}$ to SW 


\section{Natural History of Snow River Passage}

- Large passage forms

- Silt \& clay deposited on walls/floor

- Sand \& pebbles deposited

- Mn-oxide on walls

- Snowy Rivercalcite 
Ferromanganese
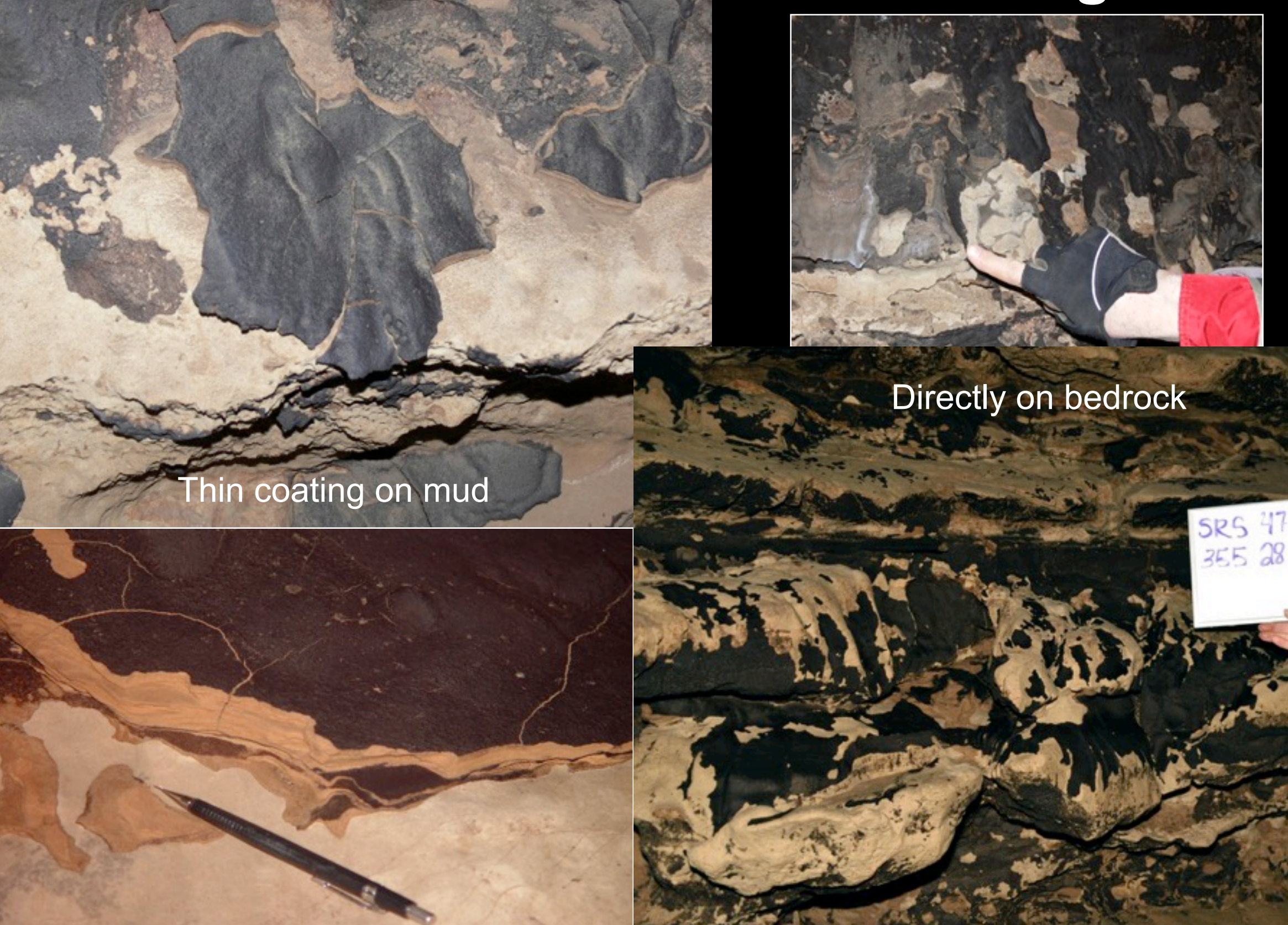

Evidence of multiple episodes of growth
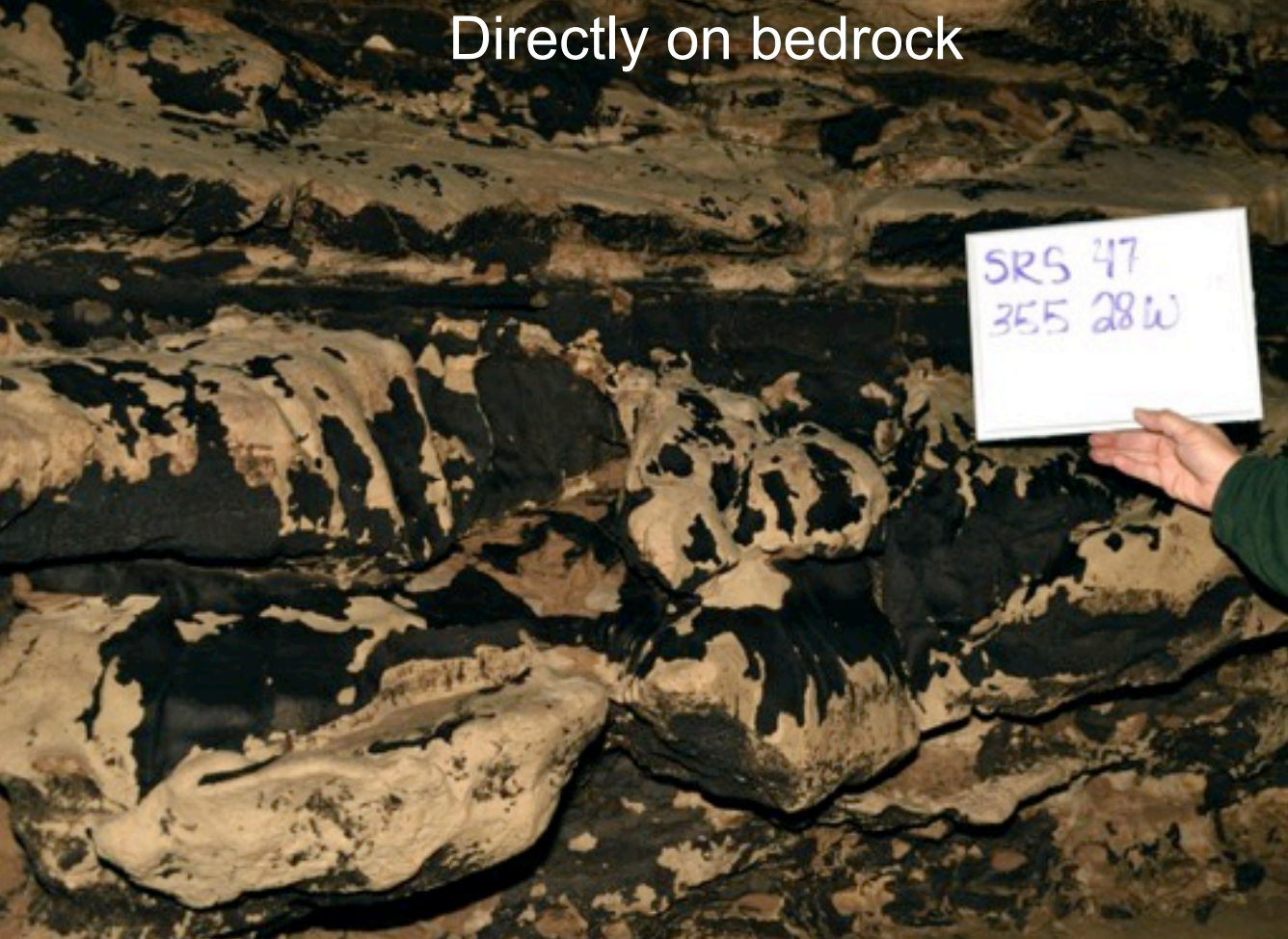

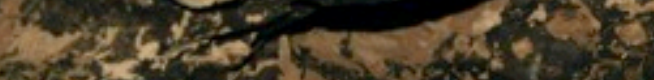

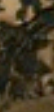




\section{Ferromanganese Coatings}

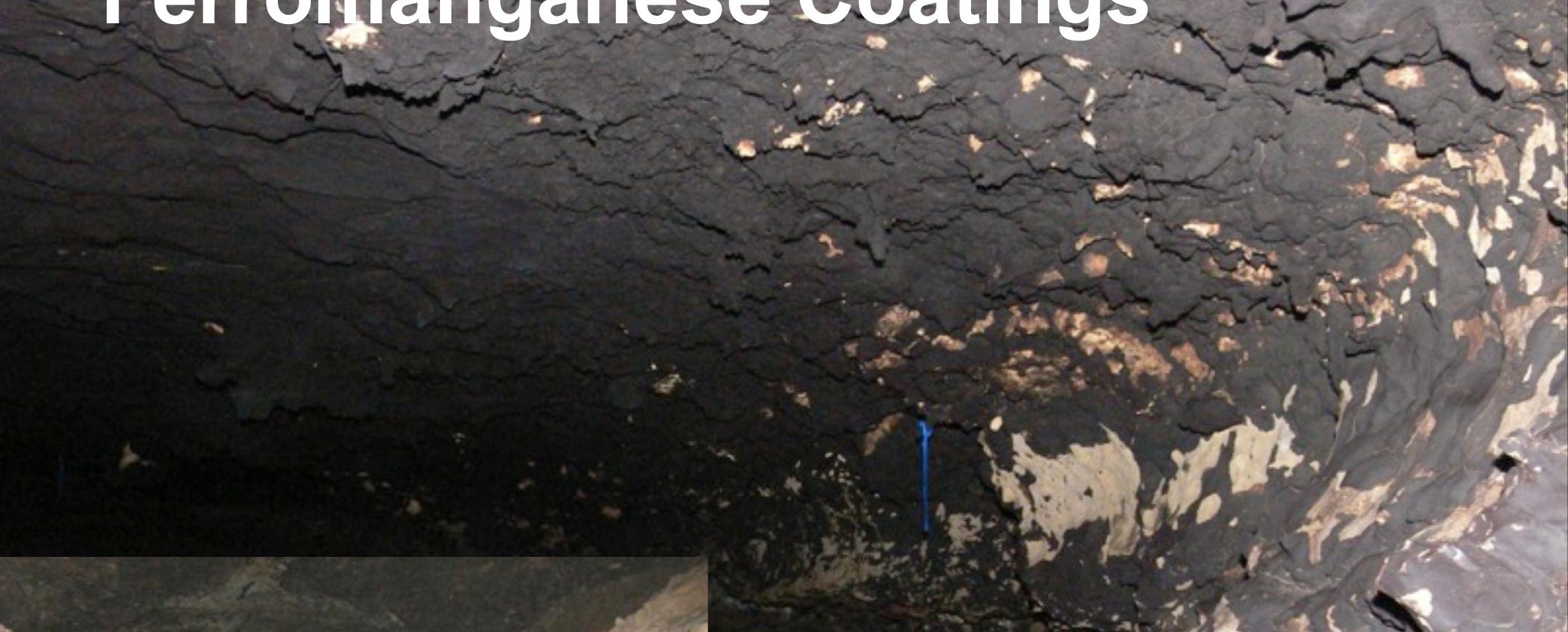

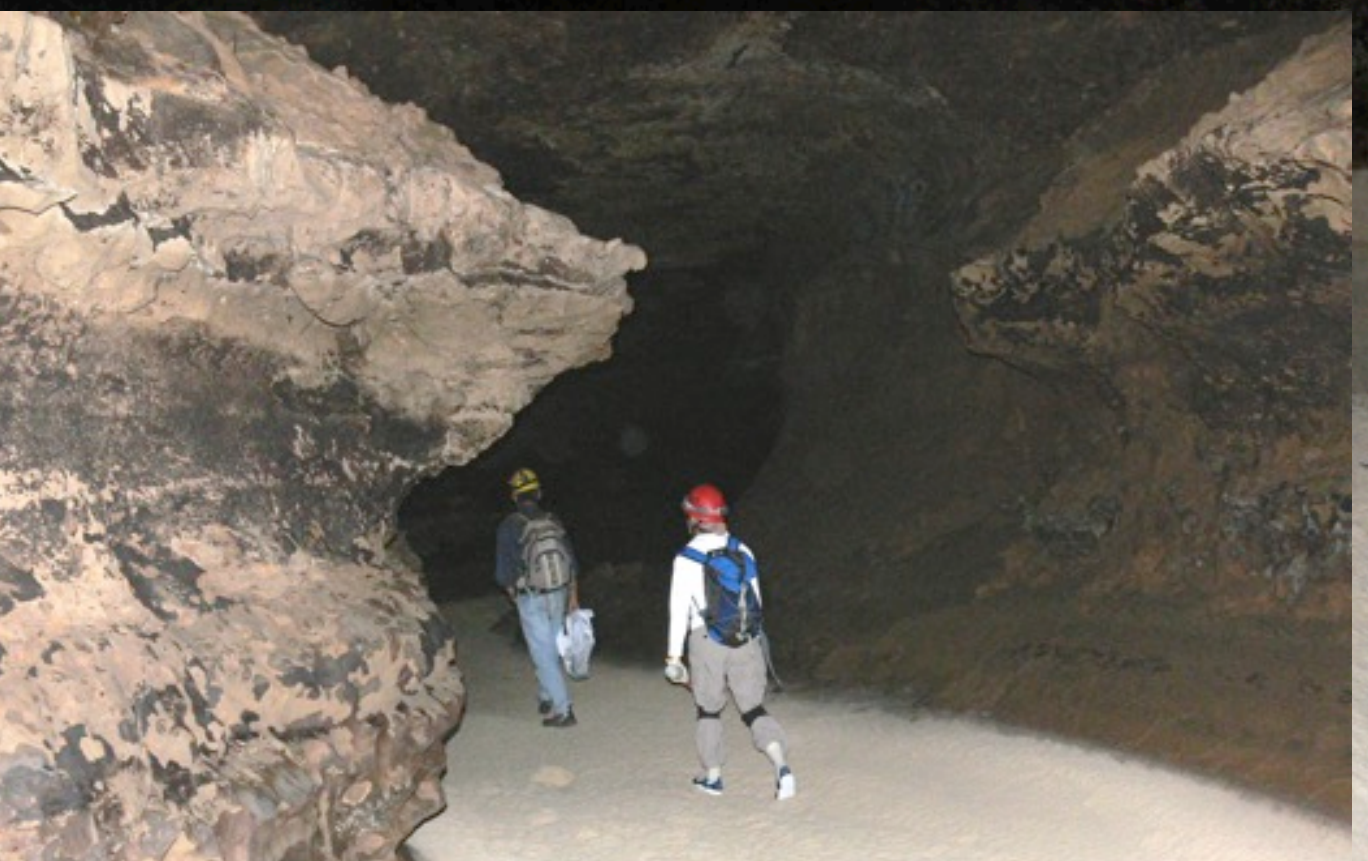

May be patchy and discontinuous
Or cover nearly every surface

Victor Polyak Photos 


\section{W 25 F Fromanganese Coatings}

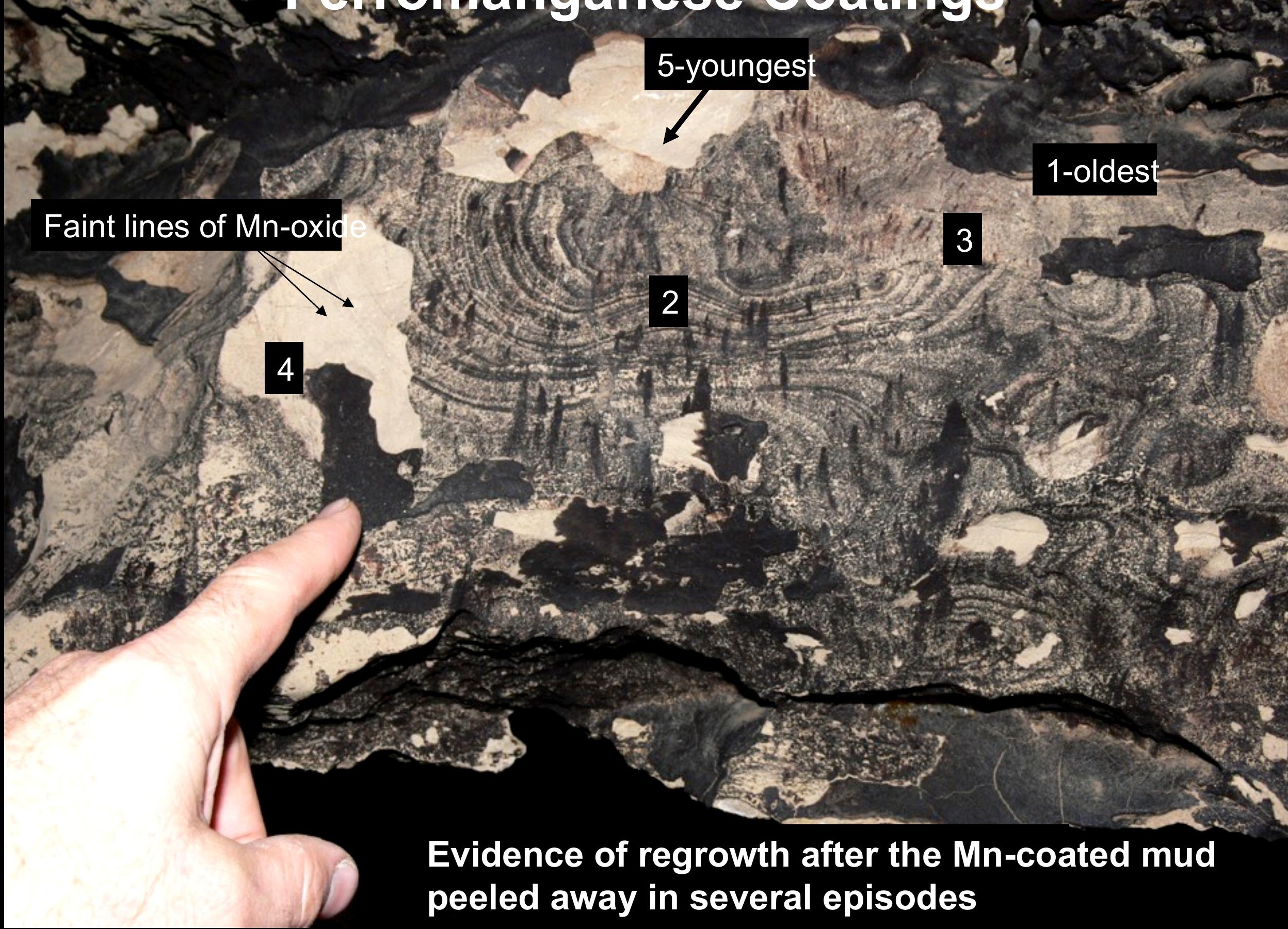




\section{SE image
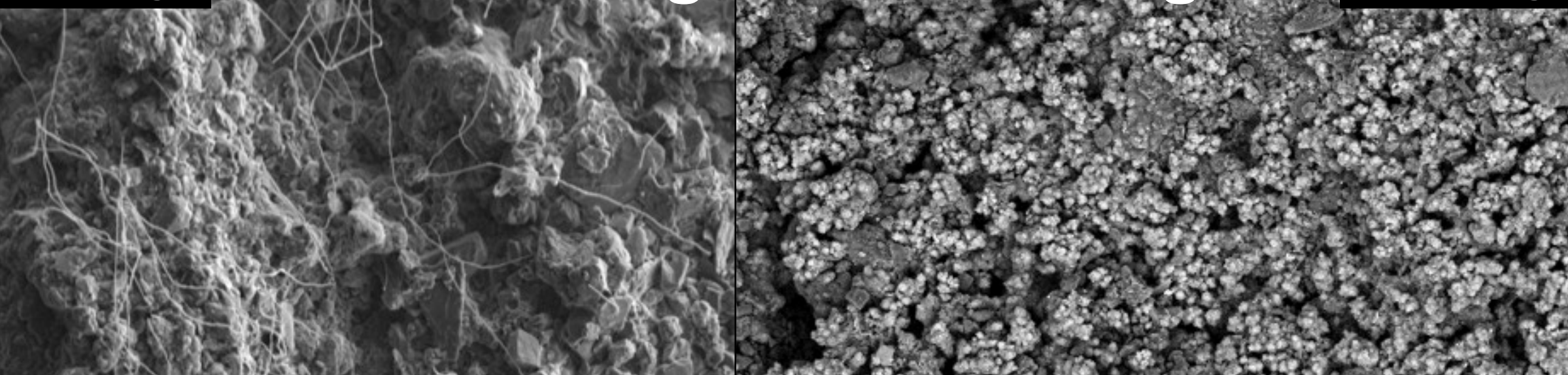

ind

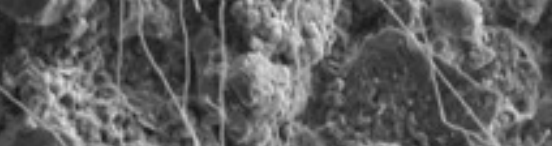
(1) Mingolain flaments
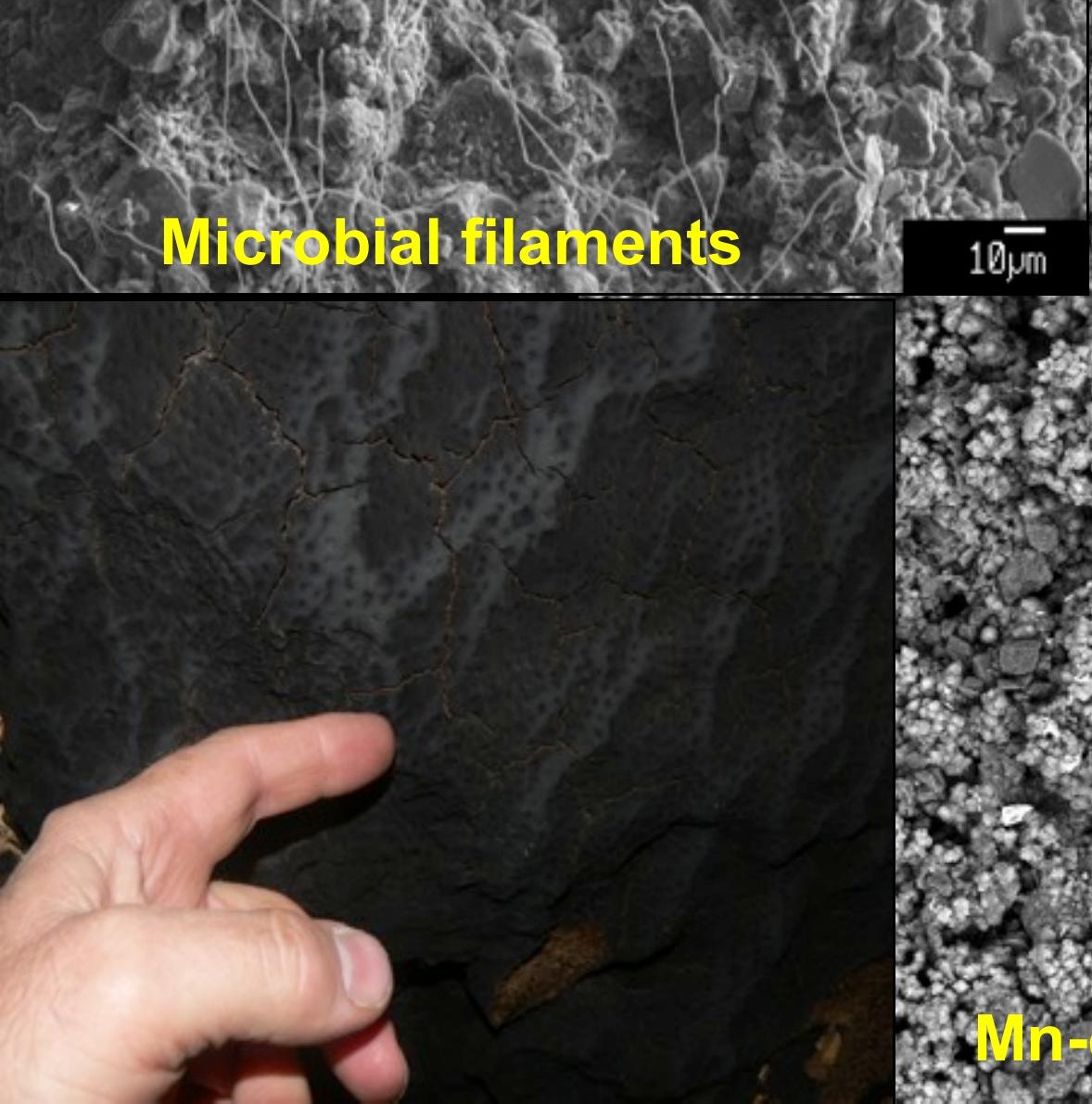

10,

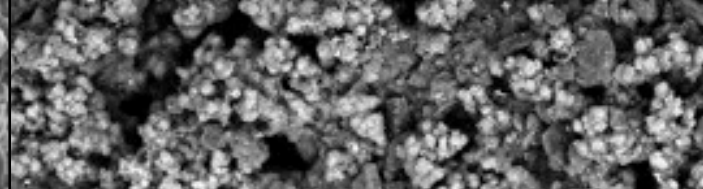

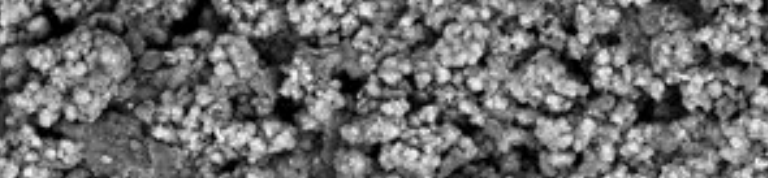

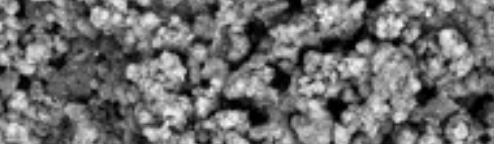

$4 \frac{3}{6}$

8 3 


\section{EPMA Analysis of FMD}

- Polished section prepared without carbon-based epoxy

- Section of Mn-oxide crust on mud collected from cave

- Sample vacuum impregnated with Na-silicate solution

- Evaporated copper used for conductive coating instead of carbon for electron probe analysis

\begin{tabular}{|l|l|l|l|l|l|l|l|l|l|}
\hline & $\mathrm{CO}_{2}$ & $\mathrm{Na}_{2} \mathrm{O}$ & $\mathrm{MgO}$ & $\mathrm{Al}_{2} \mathrm{O}_{3}$ & $\mathrm{SiO}_{2}$ & $\mathrm{~K}_{2} \mathrm{O}$ & $\mathrm{CaO}$ & $\mathrm{MnO}_{2}$ & $\mathrm{Fe}_{2} \mathrm{O}_{3}$ \\
\hline $\begin{array}{l}\mathrm{Mn} \text { - } \\
\text { oxide }\end{array}$ & 5.00 & 7.91 & 2.06 & 5.13 & 20.48 & 0.59 & 1.70 & 42.06 & 4.67 \\
\hline $\begin{array}{l}\text { Mn- } \\
\text { oxide }\end{array}$ & 3.54 & 8.52 & 1.52 & 6.25 & 15.54 & 0.50 & 1.86 & 48.18 & 4.17 \\
\hline Clay & 0.61 & 2.74 & 1.10 & 14.24 & 66.40 & 1.96 & 0.90 & 2.57 & 5.24 \\
\hline
\end{tabular}




\section{EPMA Mapping of FMD}

C

- X-ray maps on polished section

- Higher carbon associated with FMD

- Maps show 2 layers of FMD crust

- Crust inundated with mud then regrowth

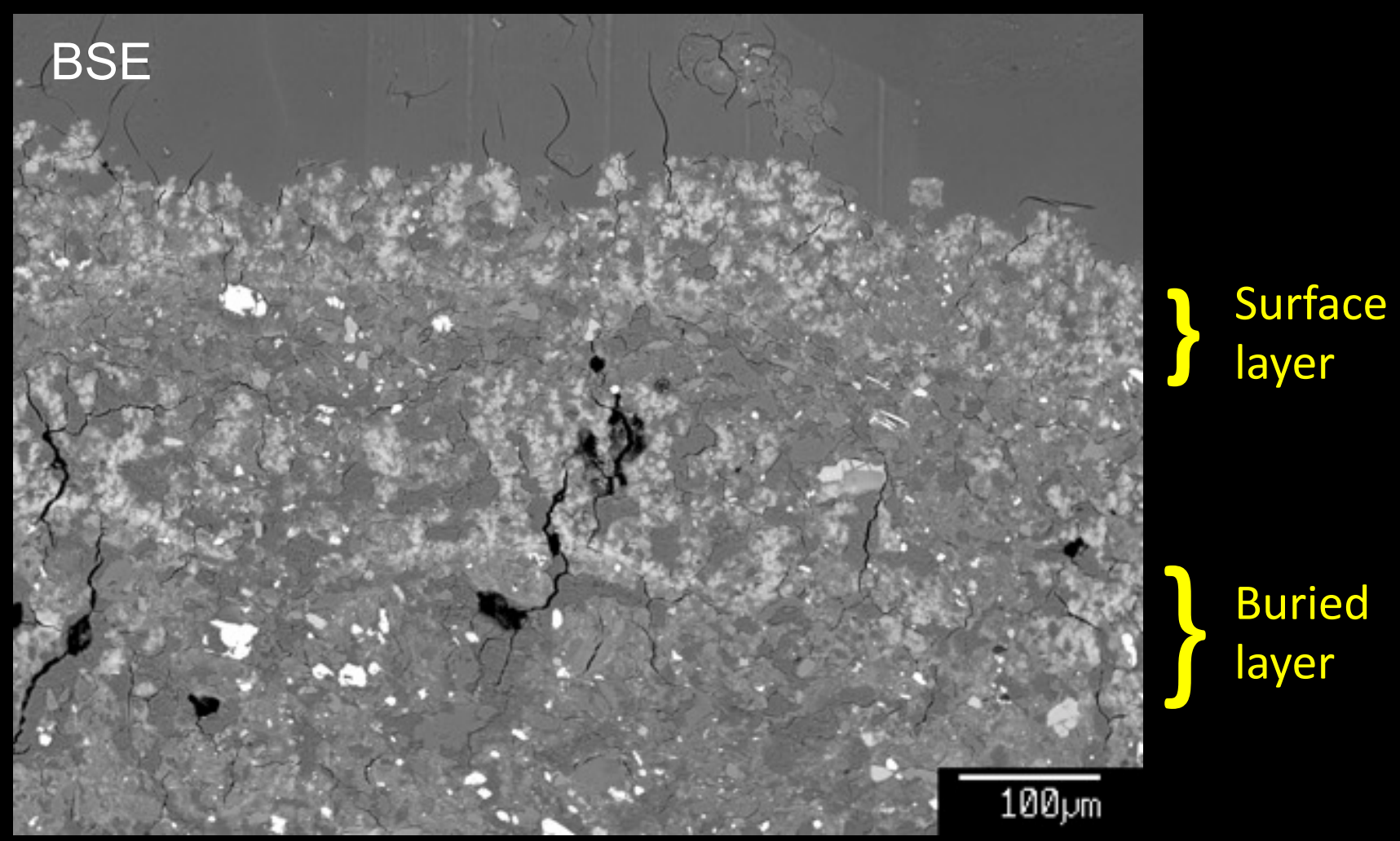

$\mathrm{Mn}$

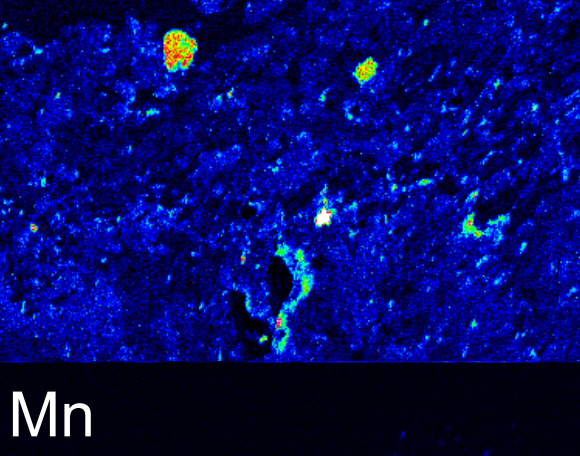

ind

wistest

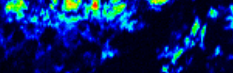




\section{Metagenomic Dataset from FMD}

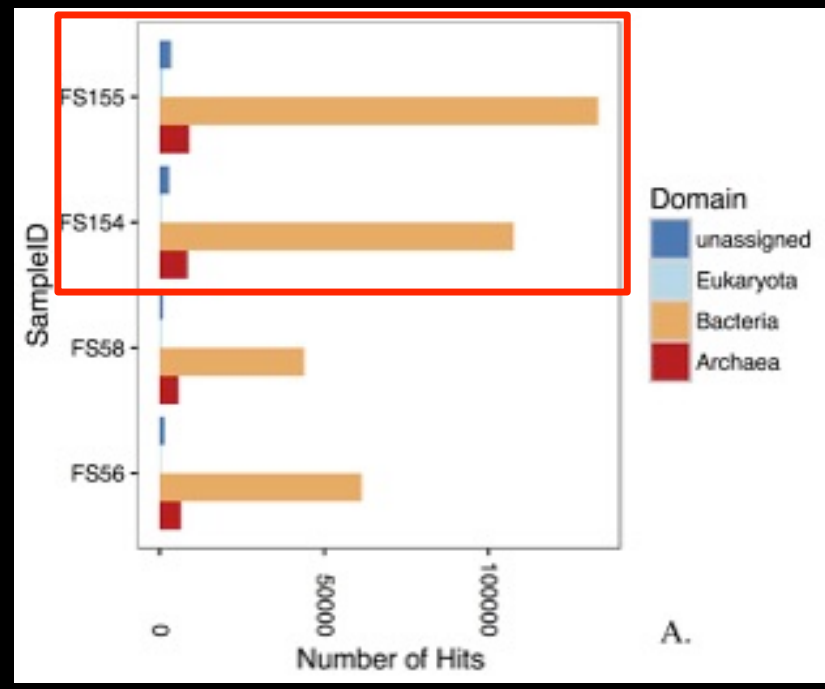

Number of hits for each domain

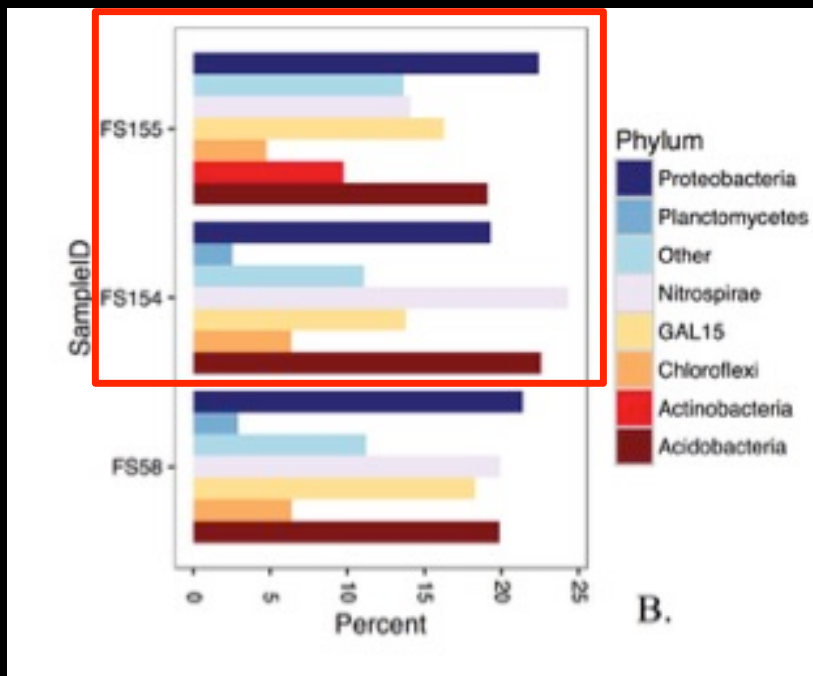

Top six bacterial phyla

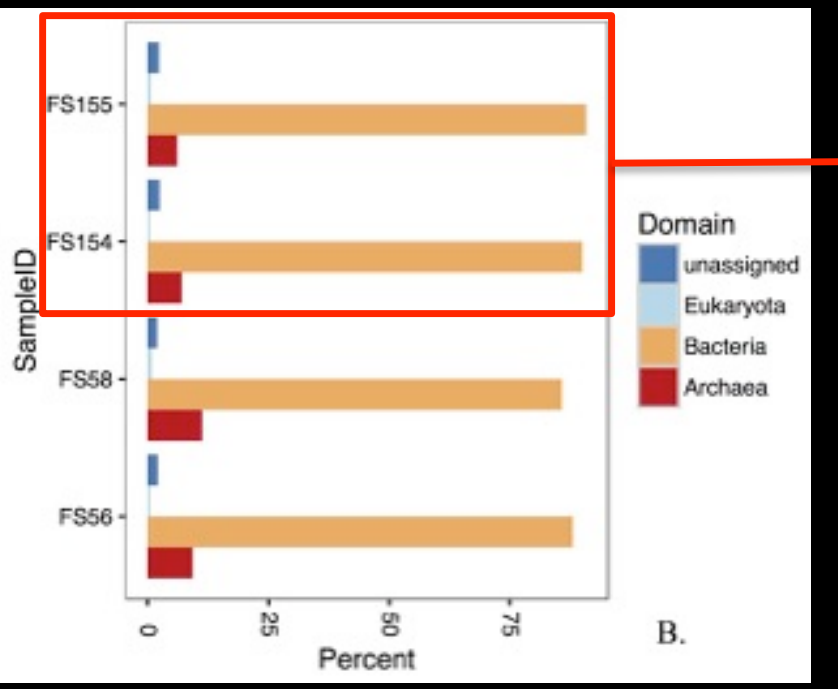

By percent of each domain

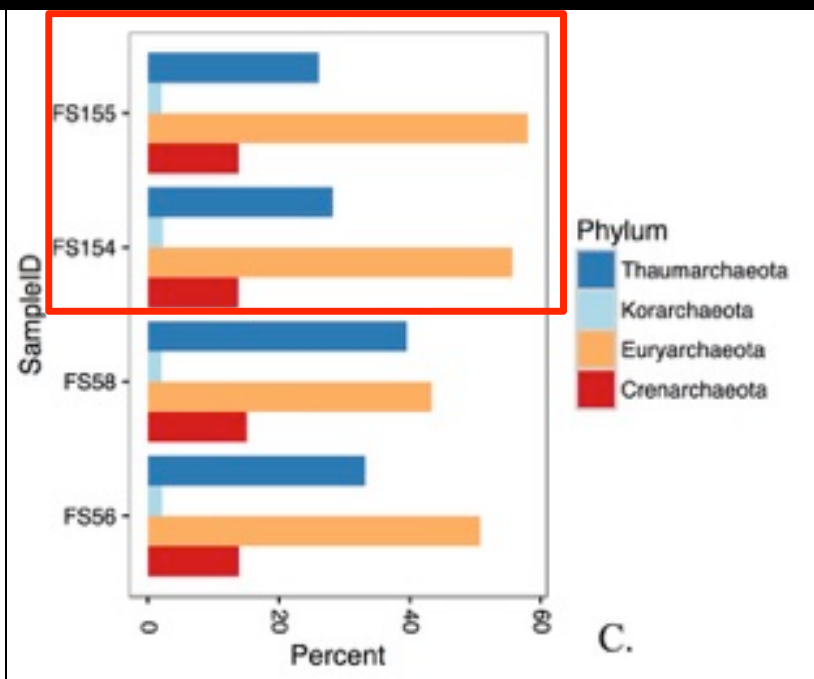

Top archaeal phyla
Black coating 


\section{Mn Oxidation in Oligotrophic Cave Systems}

Chemolithoautotrophy Model

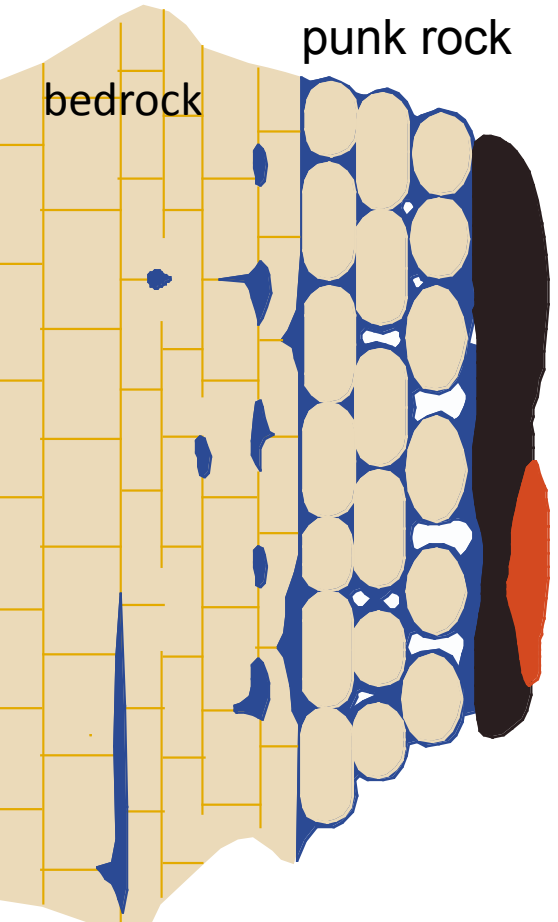

Cave Wall oxidation driven by

chemeolithoautotrophic

bacteria

oxide layer

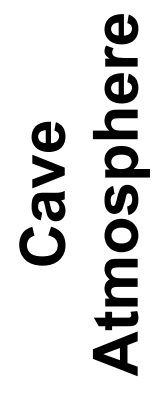

Mn oxidation driven by chemolithoautotrophic bacterial breakdown of bedrock (hypogene caves)

\section{Heterotrophy Model}

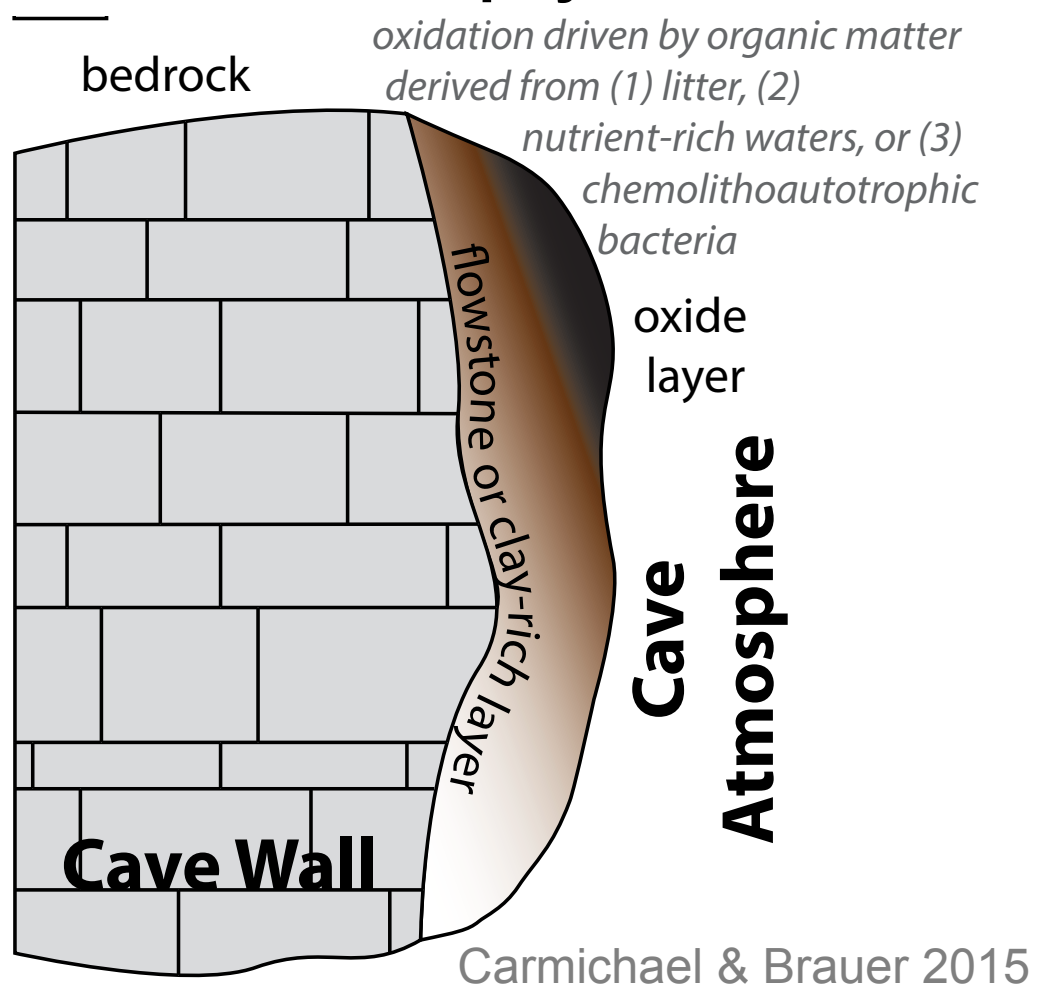

Mn oxidation driven by nutrient input from exogenous carbon in water, clay, etc. (epigene caves) 


\section{Conclusions}

- Careful preparation of samples allows EPMA analysis of carbon

- FMD is associated with higher carbon, likely the result of microbial activity

- Microbial community in FMD is dominated by heterotrophic bacteria, chemolithoautotrophs rare

- Nutrients/metals supplied by water \& detrital material

- FMD deposition has continued over time and is still active in the cave 


\section{Acknowledgements}

- Funding by NASA Exobiology for EPMA \& SEM analysis

- BLM (Knutt Peterson, Roswell Office) for cave access \& sampling permits

- Funding \& assistance from Fort Stanton Cave Study Project (Steve Peerman, Director)

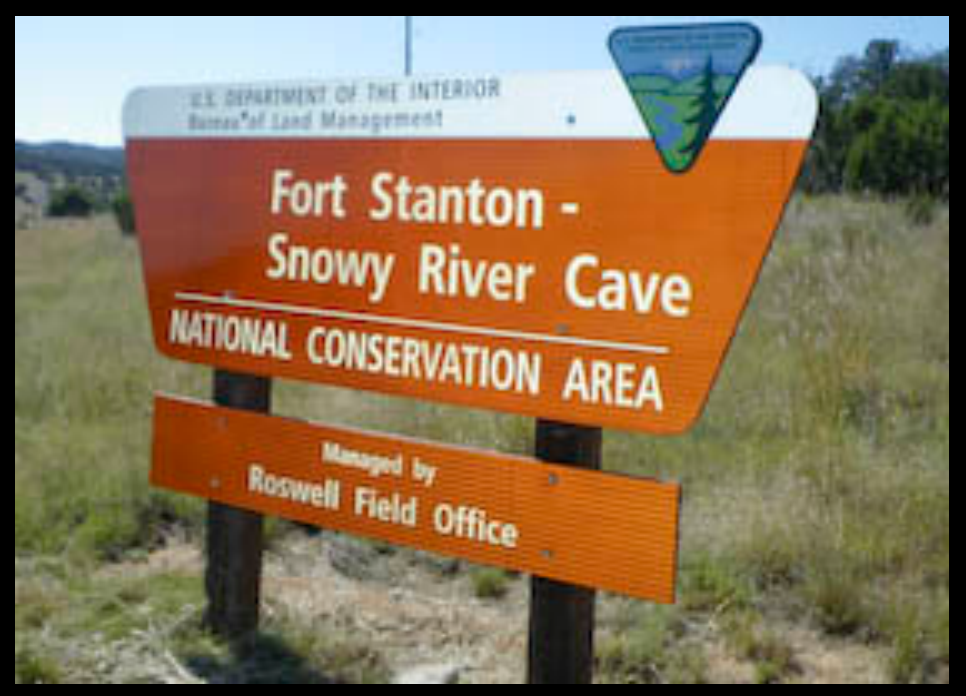

